\title{
Literatuuronderzoek naar de houding tegenover de psychometrische kwaliteit van portfolio's in het medisch onderwijs
}

\author{
J. Beullens, A. Deketelaere, E. Struyf
}

\section{Samenvatting}

Inleiding: Het portfolio is een verzameling van materiaal dat aantoont dat leren heeft plaats gehad. Het voorbije decennium is in het medisch onderwijs in toenemende mate gebruik gemaakt van dit instrument. In deze publicatie worden aan de hand van de literatuur het belang en de waarde van het portfolio in het medisch onderwijs in kaart gebracht.

Methode: Uit zoekacties in Medline en PsycInfo met 'portfolio' als zoekwoord werden alleen artikelen betreffende het medisch onderwijs verzameld.

Resultaten: Het portfolio is op alle niveaus van de medische opleiding doorgedrongen. Definitie en functie hangen af van de onderwijscontext, het opleidingsniveau en de bedoeling van de opleiders. Het portfolio wordt altijd gebruikt als leermiddel en vaak ook als summatief evaluatie-instrument. De houding van studenten en begeleiders tegenover het portfolio varieert sterk naargelang het onderzoek, en binnen hetzelfde onderzoek naargelang het beoordeelde element. Het oordeel van docenten en examinatoren is vaak gunstiger dan dat van studenten. De bezorgdheid van de studenten betreft vooral de concrete uitwerking. De psychometrische kwaliteit en met name de betrouwbaarheid is nog te laag voor een verantwoorde summatieve evaluatie.

Discussie: Meer onderzoek is vereist om het probleem van de twijfelachtige betrouwbaarheid op te lossen. Inzake het portfolio als evaluatie-instrument zijn drie houdingen mogelijk: (1) alleen gebruiken bij formatieve evaluatie, (2) trachten te voldoen aan de gebruikelijke eisen van psychometrische kwaliteit of (3) zoeken naar een alternatieve vorm van kwaliteitswaarborging. (Beullens J, Deketelaere A, Struyf E. Literatuuronderzoek naar de houding tegenover en de psychometrische kwaliteit van portfolio's in het medisch onderwijs. Tijdschrift voor Medisch Onderwijs 2004;23(4): 186-195.)

\section{Inleiding}

Er zijn instrumenten nodig om het leren in de werkomgeving van het latere beroep bijvoorbeeld tijdens stages of in de vervolgopleiding - te faciliteren, in kaart te brengen en te evalueren. De laatste jaren wordt het 'portfolio' naar voor geschoven als een in dit verband bruikbaar instrument. Het portfolio wordt voorgesteld als een collectie van bewijzen dat leren heeft plaats gehad. Het gaat om een verzameling van gevarieerd materiaal dat de professionele groei illustreert. ${ }^{1}$ De eerste presentatie van het portfolio in de medische literatuur dateert van $1993 .{ }^{2}$ Sindsdien werd in heel wat artikelen gepleit voor de introductie van het portfolio in het medisch onderwijs. Het wordt tijd om het belang en de waarde van het portfolio in de medische basis- en beroepsopleiding in kaart te brengen.

In deze publicatie wordt aan de hand van de literatuur een antwoord gezocht op de volgende vragen:

- Wat is een portfolio en wat is haar functie?

- Hoe is de houding van studenten en docenten tegenover (de introductie van) het portfolio?

- Wat is bekend over de psychometrische kwaliteit van het portfolio? 


\section{Methode}

Het vertrekpunt vormde een zoektocht naar artikelen met als zoekwoord 'portfolio' in twee zoekprogramma's: in Medline voor de periode van 1966 tot en met 2003 en in PsycInfo voor de jaren 1967 tot en met 2003. Dit leverde 580 referenties op in Medline en 435 in PsycInfo. Verder werd het Tijdschrift voor Medisch Onderwijs (TMO) doorlopen. Dit leverde 4 artikelen op. In eerste instantie werden via titel, tijdschrift en indien nodig abstract alleen artikelen betreffende het medisch onderwijs verzameld. De literatuurlijsten van deze artikelen werden doorgekeken op zoek naar andere relevante publicaties. In zoverre publicaties uit andere domeinen hielpen om het beeld te vervolledigen door bijvoorbeeld de definitie te verhelderen - werden ook deze in rekening gebracht, zonder dat een exhaustief overzicht over het portfolio in het algemeen nagestreefd werd.

\section{Resultaten}

In de medisch onderwijskundige literatuur vonden wij 29 artikelen over het portfolio. In de eerste publicatie (daterend van 1993) werd het portfolio gebruikt als een leer- en examineerinstrument in een beroepsopleiding palliatieve geneeskunde. ${ }^{2}$ Ondertussen is het portfolio in alle geledingen van de medische opleiding doorgedrongen: in de bachelor- en de masteropleiding en vooral in de beroepsopleiding en de permanente vorming, en dit zowel in het theoretisch onderwijs als in de stage. In de beroepsopleiding en de permanente vorming wordt beroep gedaan op het portfolio, zowel in de opleiding van huisartsen als in die van (andere) specialisten.

De dertien onderzoeken waarin de houding tegenover of de kwaliteit van het portfolio werden bestudeerd, zijn opgenomen in tabel 1.1 3-14 De studies hadden vooral plaats in de permanente vorming
(5) en de klinische jaren (4), minder in de beroepsopleiding (2) of de preklinische jaren (2). De meeste onderzoeken werden in het Verenigd Koninkrijk (9) uitgevoerd en op één na betroffen ze alle een papieren portfolio (12).

De vier artikelen uit het TMO betroffen geen onderzoeken, maar beschrijvingen van het gebruik van het portfolio in concrete opleidingssituaties ${ }^{15-17}$ of een redactioneel standpunt. ${ }^{18}$ Verder hadden vijf artikelen in de Engelstalige literatuur het karakter van beschrijvingen, 2 19-22 drie artikelen waren onderwijsgidsen 23-25 en vier hadden de vorm van commentaarstukken. ${ }^{26-29}$ (Zie tabel 1)

\section{Definitie en functie}

\section{Definitie}

In de literatuur zijn verschillende definities gangbaar die verschillende kenmerken benadrukken. De definitie "A portfolio may be described as a collection of evidence maintained and presented for a specific purpose" legt een verband tussen het portfolio en onderwijsdoelstellingen. ${ }^{6}$ Deze omschrijving uit een artikel in Medical Education kan aangevuld worden met andere belangrijke kenmerken geformuleerd in artikelen afkomstig van buiten de medisch-onderwijskundige literatuur. De bepaling "A portfolio is a purposeful collection of student work that exhibits the student efforts, progress, and achievements in one or more areas" benadrukt de longitudinale dimensie. ${ }^{30}$ De definitie "The portfolio represents a container of collected evidence from which the teacher can determine the students' attainment of knowledge, attitudes, and skills in the content areas of health education" herinnert er aan dat het portfolio een idee kan geven van zowel kennis, vaardigheden als attituden verworven door de student. ${ }^{31}$ De specificatie "The portfolio helps the learner to 


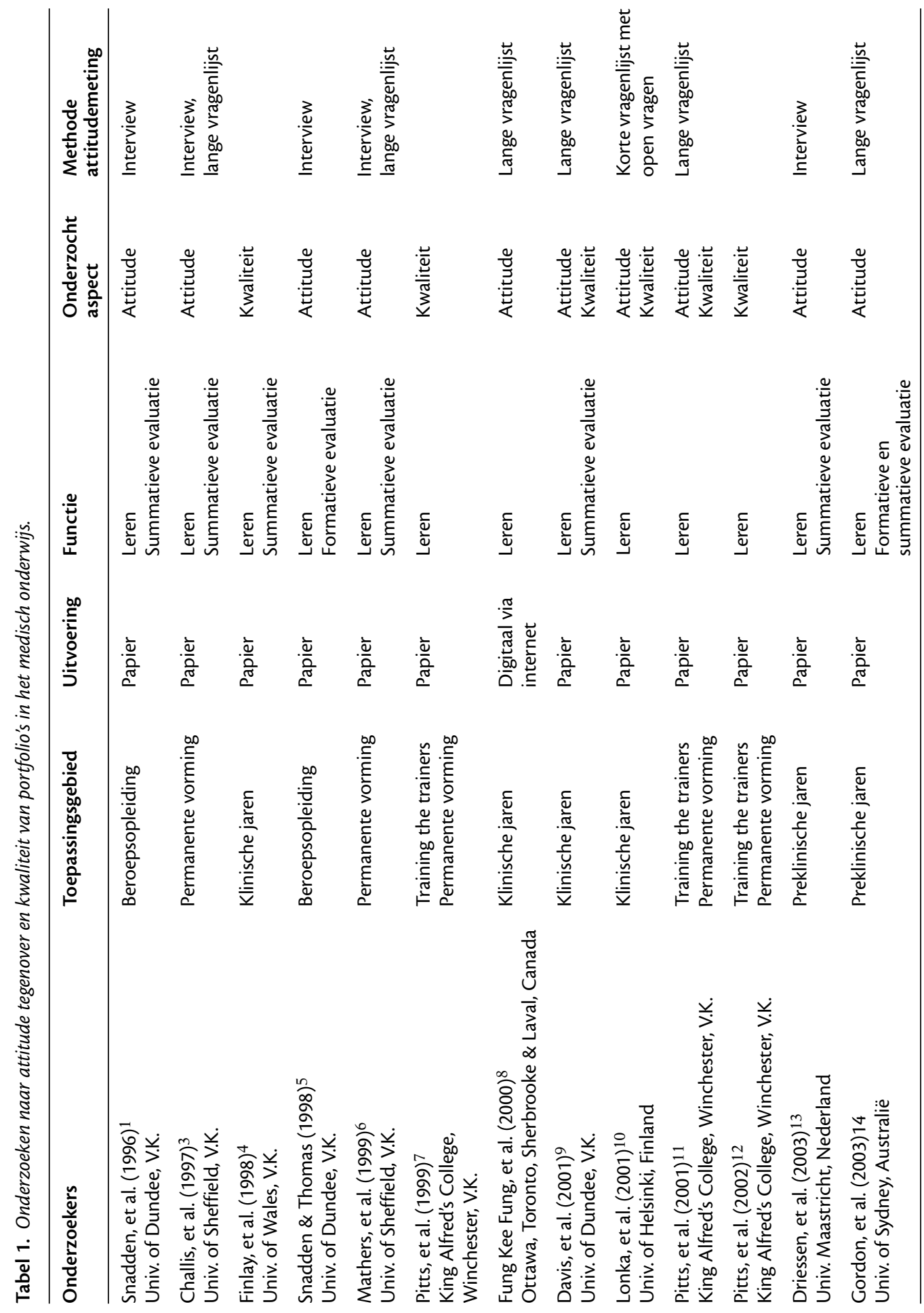


extract learning from the experience by analytic reflection" reveleert het belang van het reflecteren over het leren. ${ }^{32}$

Het doel van het portfolio is inderdaad om het leren te demonstreren en niet louter een reeks van ervaringen te inventariseren. ${ }^{24}$ Wij vatten deze definities samen als: het portfolio is een doelgerichte verzameling van door de student zelf geselecteerd werk, dat zijn/ haar bereikte niveau van kennis, attitude en vaardigheid in kaart brengt, de evolutie daarvan over een zekere periode en zijn/ haar reflecties daaromtrent. Deze bepaling omvat de vier handelingen die aan het portfolio ten grondslag liggen: verzamelen, selecteren, reflecteren en presenteren. ${ }^{21}$

\section{Functie}

Snadden en Thomas kennen het portfolio drie functies toe: 23

- Hulpmiddel bij de persoonlijke ontwikkeling (zonder begeleiding door een docent).

- Leermiddel (met begeleiding).

- Formeel toetsinstrument.

Deze evaluatie (de portfolio als formeel toetsinstrument) kan de vorm aannemen van een formatieve evaluatie (feedback geven tijdens de rit ter bevordering van het leren) of van een summatieve evaluatie (punten geven aan het einde van de rit ter beoordeling van het leren). In de gevonden onderzoeksrapporten wordt het gebruik van het portfolio altijd op één of andere wijze begeleid, zodat de eerstgenoemde functie niet van toepassing is. In de meeste gevallen werden beide andere functies gecombineerd. Het portfolio werd altijd gebruikt als leermiddel en vaak ook als evaluatie-instrument. In vijf studies functioneerde het portfolio louter als leermiddel, 78 10-12 en in zes studies tevens als instrument voor summatieve evaluatie. ${ }^{13-4} 6913$ In één studie werd - naast het portfolio als leermiddel - uitdrukkelijk haar functie in de formatieve evaluatie vermeld, 5 en in een andere was sprake van zowel formatieve als summatieve evaluatie. ${ }^{14}$

\section{Houding van studenten en docenten}

Tien publicaties rapporteren over onderzoeken waarin het gebruik van het portfolio op één of andere wijze werd geëvalueerd. Naar de mening van de participanten werd gepeild met behulp van een (semi-gestructureerd) interview, ${ }^{1} 513$ een korte vragenlijst met open vragen, 10 een uitvoerige vragenlijst met gesloten vragen ${ }^{8-9} 1114$ of zowel interview als vragenlijst. 36

Uit twee interviewonderzoeken krijgt men de indruk dat sommige studenten de samenstelling van het portfolio appreciëren, terwijl anderen dit percipiëren als tijdverlies. ${ }^{15}$ Hoewel het systeem meer gewaardeerd werd door docenten dan door studenten, vonden ook sommigen dat het niets nieuws meebracht. ${ }^{15}$ In het derde interviewonderzoek was het oordeel van de studenten over het portfolio gunstig. ${ }^{13}$ Leren reflecteren vereiste coaching volgens de docenten. ${ }^{13}$

In de studie waarbij de studenten door middel van open vragen gestimuleerd werden schriftelijk commentaar te geven over het portfolio, vond $50 \%$ het portfolio nuttig. Slechts $16 \%$ gaf negatief commentaar. Deze studenten vonden vooral het reflecteren over eigen ervaringen zwaar en tijdrovend. ${ }^{10}$

In drie recente onderzoeken werd na afloop de houding van studenten en docenten bevraagd door middel van een zelf samengestelde vragenlijst. Positief in de eerste studie was dat, hoewel het de meerderheid van de studenten vóór de cursus aan zelfvertrouwen ontbrak om het portfolio samen te stellen, de meerderheid dit na de cursus wel bezat. Negatief was dat, 
hoewel ongeveer de helft de schriftelijke richtlijnen in het begin van de cursus bruikbaar vond, slechts een kwart toegaf ze te gebruiken. Verder vond meer dan $90 \%$ het bijhouden van het portfolio tijdens de cursus de moeite waard en vond twee derde het portfolio een goede methode om zijn trainingservaring te ontwikkelen. ${ }^{11}$

In de tweede studie vallen vooral de meningsverschillen op tussen examinatoren en studenten. Terwijl de examinatoren het portfolio een geschikt instrument vonden voor summatieve evaluatie, omdat het de sterkten en zwakten van de studenten identificeert, waren de studenten het daar niet mee eens: het portfolio-examen gaf hun werkelijke bekwaamheid niet weer en de verwachtingen van de examinatoren waren niet duidelijk. De studenten waren er bovendien niet van overtuigd dat het portfolio een nuttige leerervaring inhield. Ze bracht te veel papierwerk mee en interfereerde met hun klinisch leren. Ook hadden ze op voorhand meer informatie gewild over de samenstelling van het portfolio. Ze vonden wel dat het mondelinge portfolio-examen goed georganiseerd was, dat de staf tijd had gespendeerd in het vertrouwd geraken met hun werk en niet alleen in hun portfolio, maar ook in henzelf geïnteresseerd was. ${ }^{9}$

In het derde onderzoek was het oordeel van de studenten erg positief. Zo vond meer dan $90 \%$ het gebruik van het portfolio de moeite waard en resulteerde dit in nuttige reflectie. Vijfentachtig procent verwierf meer inzicht in hun professioneel handelen. Drie kwart zag mogelijkheden om hun professioneel handelen te veranderen. Alle betrokken docenten vonden het inspecteren van de portfolio's en het interviewen van de studenten een positieve ervaring. ${ }^{14}$
In één studie werd bij stagiairs van vier Canadese universiteiten een reeds bestaande vragenlijst afgenomen. In één universiteit hadden de stagiairs ondertussen ervaring opgedaan met een elektronisch portfolio, in de andere drie universiteiten niet. In vergelijking met hun collega's uit deze drie universiteiten rapporteerden meer stagiairs uit de eerstgenoemde universiteit cognitieve kritische incidenten, dat ze uitkeken naar levenslang leren, dat ze elk jaar zelfstandig iets nieuws leerden en dat het portfolio bijdroeg tot het leren tijdens de stage. 8

De bevindingen uit het interview plus vragenlijstonderzoeken benadrukken vooral de gunstige evolutie in de loop van de tijd: naar het einde van de termijn toe werden over het algemeen de verwachtingen vervuld en verdwenen de onzekerheden en angsten. De verwachtingen betroffen onder meer de identificatie van leerbehoeften, de relevantie voor de praktijk en de stimulering van persoonlijke studie. Onzekerheden en angsten hadden onder andere te maken met de inhoud van het portfolio, de hoeveelheid werk en de tijdsinvestering. 36

\section{Psychometrische kwaliteit}

In de praktijk varieert een staal portfolio's afkomstig van verschillende individuen erg in omvang, structuur, opgenomen materiaal en diepte van de reflectie. ${ }^{11}$ In de helft van de onderzochte leersituaties werden punten toegekend aan het portfolio (zie tabel 1). Indien het portfolio gebruikt wordt als summatief evaluatie-instrument, dan dient deze te voldoen aan welbepaalde psychometrische eisen. Om in aanmerking te komen voor een summatieve evaluatie dient de informatie die het portfoliomateriaal inhoudt een betrouwbaar en valide oordeel mogelijk te maken. ${ }^{33}$ De be- 
trouwbaarheid en de validiteit kunnen op verschillende wijzen gemeten worden. In de gevonden onderzoeken werd doorgaans de inter- en intrabeoordelaarsbetrouwbaarheid nagegaan. De interbeoordelaarsbetrouwbaarheid betreft de mate van overeenstemming tussen twee of meer beoordelaars. De intrabeoordelaarsbetrouwbaarheid gaat over de mate van overeenstemming tussen oordelen gevormd met enige tussentijd door dezelfde beoordelaar. In de verzamelde rapporten werd de begripsvaliditeit geoperationaliseerd als de correlatie tussen punten toegekend aan het portfolio en punten toegekend aan instrumenten die hetzelfde of iets anders meten.

De eigenschappen die het portfolio typeren, vormen hierbij evenwel grote hindernissen. Zo is er de contradictie tussen de vrijheid die aan de student wordt toegestaan bij de uitwerking en de standaardisatie die vereist is om een betrouwbare meting te bekomen. De ambitie om niet alleen het moeilijk meetbare concept 'attitude' te meten, maar bovendien kennis en vaardigheid, is hooggegrepen. Eén betrouwbare en valide meting volstaat niet; verschillende oordelen over hetzelfde portfolio zijn nodig om de evolutie in kaart te brengen. Ten slotte is er nog het probleem van het inschatten van het reflectievermogen.

Wellicht mede door deze hindernissen is de psychometrische kwaliteit van het portfolio zelden onderzocht. In 1994 vonden Herman en Winters dat van de 89 artikelen over het gebruik van het portfolio in het onderwijs als meetinstrument die ze aantroffen in de voorgaande 10 jaar, er slechts zeven technische gegevens rapporteerden of aanvaarde onderzoeksmethoden gebruikten. ${ }^{34}$ Herman en Winters stelden inconsistente bevindingen vast in- zake de betrouwbaarheid en ontmoedigende inzake de validiteit van het portfolio in het onderwijs.

In de medisch onderwijskundige literatuur van het voorbije decennium vonden wij slechts zes studies waarin de betrouwbaarheid en/ of validiteit van het portfolio werd onderzocht. Eén onderzoek was gerandomiseerd en gecontroleerd. ${ }^{4}$ In twee studies werd de begripsvaliditeit nagegaan. ${ }^{9-10}$ In drie studies van dezelfde onderzoeksgroep werd de betrouwbaarheid bestudeerd. ${ }^{71-12}$ In het eerste hiervan beoordeelden acht ervaren huisartstrainers portfolio's betreffende zes aspecten en in hun totaliteit. ${ }^{7}$ De betrouwbaarheid tussen de beoordelaars onderling was zwak tot matig met kappa's tussen 0,10 en 0,41 . De gemiddelde correlatie tussen twee scores van dezelfde beoordelaar, gegeven met een maand tijd tussenin, was middelmatig met kappa's tussen 0,38 en 0,54. ${ }^{7}$ Een replicatie van dit onderzoek met behulp van de portfolio's van het daaropvolgende jaar leverde gelijkaardige resultaten op. De correlatie tussen de acht ervaren huisartstrainers was zwak tot matig met kappa's tussen 0,13 en 0,42 voor de zes aspecten. De intrabeoordelaarsbetrouwbaarheid met een maand tussentijd was middelmatig met kappa's tussen 0,21 en 0,48 voor de aspecten en 0,54 globaal. Ongeveer de helft van de beoordelingscriteria bij het begin van de cursus was nuttig en slechts een kwart gebruikte deze effectief. ${ }^{11}$ In het derde onderzoek van Pitts en medewerkers beoordeelden acht ervaren huisartstrainers eveneens portfolio's op zes aspecten en globaal. ${ }^{12}$ Twee maanden na de onafhankelijke beoordeling moesten ze in toevallig samengestelde paren de portfolio's opnieuw scoren en deze scores bespreken tot ze overeenstemming bereikten. Bij individuele beoordeling lagen de 
kappa's voor de zes aspecten tussen 0,05 en 0,36 , bij paarsgewijze beoordeling tussen 0,01 en 0,65 . De overeenstemming over de globale score steeg van 0,26 bij afzonderlijke beoordeling tot 0,50 bij gezamenlijke beoordeling. De betrouwbaarheid leek dus toe te nemen door in paren een globale score toe te kennen aan het portfolio. 12

De begripsvaliditeit werd bestudeerd in de laatste twee jaren van de medische opleiding in Dundee, tijdens dewelke het portfolio wordt opgebouwd. De opleiding bestaat in het vierde jaar hoofdzakelijk uit stages en in het vijfde uit klinisch onderwijs. De totale score voor het portfolio correleerde 0,42 met de score op extended-matchingvragen (EMQ, een vorm van meerkeuzevragen), 0,42 met een 'constructed response question' (CRQ), 0,47 met een 'objective structured clinical examination' (OSCE of stationstoets) en 0,34 met het stageblok psychiatrie; al deze scores werden (met uitzondering van deze op het portfolio) in het voorlaatste jaar toegekend. Het portfolio mat dus gedeeltelijk kennis (EMQ), probleemoplossend vermogen (CRQ) en klinische vaardigheden (OSCE). ${ }^{9}$

In Helsinki werd het portfolio gebruikt tijdens een training verloskunde/ gynaecologie in het vijfde jaar van de medische opleiding. Deze training omvatte contactmomenten voor zowel theorie als stage. Hoe meer de studenten in hun portfolio schreven, hoe hoger hun eindscore van dat jaar was. De hoeveelheid geschreven tekst in het portfolio correleerde 0,34 met het aantal uitgevoerde vaginale onderzoeken en 0,29 met het aantal externe foetale onderzoeken. ${ }^{10}$ Het is mogelijk dat de meest actieve studenten beter presteerden zowel in eindscore, in aantal uitgevoerde onderzoeken als in hoeveelheid portfoliotekst.
Het enige gerandomiseerde, gecontroleerde onderzoek betreffende het portfolio in het medisch onderwijs had plaats in het kankeronderwijs in de kandidaturen (coassistentschappen). Elke student volgde een kankerpatiënt gedurende ten minste 9 maanden en dit proces werd begeleid via tweemaandelijkse tutorials. De experimentele groep hield een portfolio bij, de controlegroep niet. Het stond de studenten uit de experimentele groep vrij het portfolio in te dienen voor formatieve evaluatie. De experimentele en de controlegroep verschilden niet significant in hun totaalscore op de stationsproef. De studenten uit de experimentele groep die een portfolio indienden, hadden evenwel een significant hogere score op drie OSCE-stations dan hun collega's uit de experimentele groep die dit niet deden. ${ }^{4}$ Dit verschil kan natuurlijk ook te wijten zijn aan andere factoren, zoals een hogere studiemotivatie bij de portfolio-indieners.

\section{Discussie}

Sinds de jaren negentig wordt op alle niveaus van de medische opleiding gebruik gemaakt van het portfolio. Definitie en functie verschillen naargelang onder meer de onderwijscontext, het opleidingsniveau en de bedoeling van de opleiders. Het portfolio wordt altijd gebruikt als leermiddel en vaak ook als summatief evaluatie-instrument.

Het oordeel over het portfolio varieert sterk (van positief tot negatief) al naargelang het onderzoek en binnen hetzelfde onderzoek al naargelang het beoordeelde aspect. De verschillen tussen de studies zijn natuurlijk mee te wijten aan de concrete uitwerking van de portfolioformule en de gebruikte evaluatiemethode. Toch kunnen enkele algemene conclusies getrokken worden. Zo is het oordeel van de docenten vaak gunstiger dan dat van de 
studenten. Ook in een examineersituatie vinden de examinatoren het portfolio een geschikter evaluatie-instrument dan de examinandi. Dit heeft belangrijke praktische consequenties. Het betekent namelijk dat indien men bij de implementatie het docentencorps achter het portfoliovaandel kan krijgen, de strijd nog niet half gestreden is. De weerstand bij de studenten kan zijn. De negatieve houding van de studenten betreft niet zozeer het globale oordeel (het bijhouden van het portfolio wordt vaak de moeite waard gevonden en stimuleert vaak de studie), maar wel de concrete realisering, met name de onzekerheid over wat in het portfolio kan opgenomen worden en de vrees dat dit te tijdrovend is. Verder vinden de studenten reflecteren moeilijk en het gebruik van het portfolio voor summatieve evaluatie soms problematisch. Bij de introductie van het portfolio mag het verstrekken van concrete informatie aan de studenten bijgevolg niet onderschat worden. Ten slotte evolueert de mening van de studenten vaak in gunstige richting, maar vergt dit enige tijd.

Indien het portfolio gebruikt wordt in het kader van een summatieve evaluatie, dan moet deze aan psychometrische eisen voldoen inzake betrouwbaarheid en validiteit. Het blijkt moeilijk te zijn om tot een betrouwbaar oordeel te komen. De overeenstemming tussen verschillende beoordelaars of bij dezelfde beoordelaar op verschillende tijdstippen is in de regel zwak tot matig. De betrouwbaarheid lijkt groter te zijn bij globale scoring dan bij de scoring van afzonderlijke aspecten en bij de beoordeling in paren dan bij individuele beoordeling.

Er zijn enige aanwijzingen voor de begripsvaliditeit. De score op het portfolio correleert matig met scores op toetsen die kennis, probleemoplossend vermogen en klinische vaardigheden meten.
Door het probleem van de twijfelachtige psychometrische kwaliteit zijn drie houdingen mogelijk. Het eerste standpunt is dat het portfolio alleen kan gebruikt worden voor formatieve evaluatie en uitgesloten is voor summatieve evaluatie. De tweede optie is dat men via het structureren en standaardiseren van het portfolio en het systematisch trainen van de beoordelaars toch poogt een meetinstrument te verkrijgen dat voldoet aan de gebruikelijke eisen qua psychometrische kwaliteit. Werken met een globale score en paren van beoordelaars verdient hierbij aanbeveling. Volgens de derde visie zijn de gebruikelijke metingen van betrouwbaarheid en validiteit niet opportuun voor leren via het portfolio. Andere criteria die gesuggereerd worden voor het evalueren van de toetskwaliteit zijn: cognitieve complexiteit, authenticiteit, directheid, eerlijkheid en transparantie. Met cognitieve complexiteit wordt bedoeld de mate waarin het portfolio het probleemoplossen, het kritisch denken of redeneren meet. De authenticiteit betreft het realiteitskarakter van de aangeboden problemen. De directheid van assessment is de mate waarin de docenten competentie onmiddellijk kunnen beoordelen. Eerlijkheid betekent dat de studenten een eerlijke kans hebben om te tonen wat ze echt kennen en kunnen. De transparantie van de gebruikte beoordelingscriteria houdt in dat de studenten weten welke standaard gehanteerd wordt bij het beoordelen. 35

Het is niet noodzakelijk het portfolio in te schakelen in de summatieve evaluatie. Het kan gebruikt worden als formatief evaluatie-instrument. Per slot van rekening is het portfolio bedoeld om via reflectie het leren in een authentieke leeromgeving te bevorderen. 


\section{Literatuur}

1. Snadden D, Thomas ML, Griffin EM, Hudson H. Portfolio-based learning and general practice vocational training. Med Educ 1996;30:148-52.

2. Finlay IG, Stott NCH, Marsh HM. Portfolio learning in palliative medicine. Eur $\mathrm{J}$ Cancer Care 1993;2:41-3.

3. Challis M, Mathers NJ, Howe AC, Field NJ. Portfolio-based learning: continuing medical education for general practitioners: a mid point evaluation. Med Educ 1997;31:22-6.

4. Finlay IG, Maughan TS, Webster DJT. A randomized controlled study of portfolio learning in undergraduate cancer education. Med Educ 1998;32:172-6.

5. Snadden D, Thomas ML. Portfolio learning in general practice vocational training: does it work? Med Educ 1998;32:401-6.

6. Mathers NJ, Chalis MC, Howe AC, Field NJ. Portfolios in continuing medical education: effective and efficient? Med Educ 1999;33:521-30.

7. Pitts J, Coles C, Thomas P. Educational portfolios in the assessment of general practice trainers: reliability of assessors. Med Educ 1999;33:515-20.

8. Fung Kee Fung M, Walker M, Fung Kee Fung K, Temple L, Lajoie F, Bellemare G, et al. An internet-based learning portfolio in resident education: the KOALA multicentre programme. Med Educ 2000;34:474-9.

9. Davis MH, Friedman Ben-David M, Harden RM, Ker PHJ, McGhee C, Pippard MJ, et al. Portfolio assessment in medical students' final examinations. Med Teach 2001;23:357-66.

10. Lonka K, Slotte V, Halttunen M, Kurki T, Tiitinen A, Vaara L, et al. Portfolios as a learning tool in obstetrics and gynaecology undergraduate training. Med Educ 2001;35:1125-30.

11. Pitts J, Coles C, Thomas P. Enhancing reliability in portfolio assessment: 'shaping' the portfolio. Med Teach 2001;23:351-6.

12. Pitts J, Coles C, Thomas P, Smith F. Enhancing reliability in portfolio assessment: discussions between assessors. Med Teach 2002;24:197-201.

13. Driessen EW, Tartwijk J van, Vermunt JD, Vleuten CPM van der. Use of portfolios in early undergraduate medical training. Med Teach 2003;25: 18-23.

14. Gordon J. Assessing students' personal and professional development using portfolios and interviews. Med Educ 2003;37:335-40.

15. Bleys RLAW, Nieuwhof MGH. Onderdelen van CRU '99: studiereflectie. Tijdschrift voor Medisch Onderwijs 2001;20:S35-S37.

16. Carlier IVE, Leeuwen YD van. Portfoliosystematiek in de huisartsopleiding. Tijdschrift voor Medisch Onderwijs 2001;20:232-40.
17. Overeem K, Driessen EW, Tartwijk J van, Vleuten CPM van der. Portfolio om de basisarts-in-opleiding te begeleiden. Tijdschrift voor Medisch Onderwijs 2003;22:268-76.

18. Remmen R. Portfolio in medisch onderwijs: trend, valkuil of hulpmiddel? Tijdschrift voor Medisch Onderwijs 2002;21:84-7.

19. Finlay IG, Maughan TS, Webster DJT. Portfolio learning: a proposal for undergraduate cancer teaching. Med Educ 1994;28:79-82.

20. Dornan T, Lee C, Stopford A. SkillsBase: a webbased electronic learning portfolio for clinical skills. Acad Med 2001;76:542-3.

21. Driessen EW, Vleuten CPM van der. Universiteit Maastricht: portfolio's voor eerstejaars studenten geneeskunde. In Driessen EW, Beijaard D, Tartwijk J van, Vleuten CPM van der, editors. Portfolio's, Hoger Onderwijs Reeks. Groningen/ Houten: Wolters-Noordhoff; 2002. p. 37-46.

22. Supiano MA, Fantone JC, Grun C. A web-based geriatrics portfolio to document medical students' learning outcomes. Acad Med 2002;77:937-8.

23. Snadden D, Thomas M. The use of portfolio learning in medical education. Med Teach 1998;20: 192-9.

24. Challis M. AMEE Medical Education Guide No. 11 (revised): Portfolio-based learning and assessment in medical education. Med Teach 1999;21: 370-86.

25. Friedman Ben David M, Davis MH, Harden RM, Howie PW, Ker J, Pippard MJ. AMEE Medical Education Guide No. 24: Portfolios as a method of student assessment. Med Teach 2001;23: 535-51.

26. Snadden D. Portfolios - attempting to measure the unmeasurable? Med Educ 1999;33:478-9.

27. Roberts C, Newble DI, O'Rourke AJD. Portfoliobased assessments in medical education: are they valid and reliable for summative purposes? Med Educ 2002;36:899-900.

28. Wilkinson TJ, Challis M, Hobsma SO, Newble DI, Parboosingh JT, Sibbald RG, et al. The use of portfolios for assessment of the competence and performance of doctors in practice. Med Educ 2202;36:918-24.

29. Duque G. Web-based evaluation of medical clerkships: a new approach to immediacy and efficacy of feedback and assessment. Med Teach 2003;25:510-4.

30. Paulson FL, Paulson PR, Meyer CA. What makes a portfolio a portfolio? Eight thoughtful guidelines will help educators encourage self-directed learning. Educational Leadership 1991;48(5):60-3.

31. Cleary MJ. Using portfolios to assess student performance in school health education. J Sch Health 1993;63:377-81. 
32. Järvinen A, Kohonen V. Promoting professional development in higher education through portfolio assessment. Assessm Eval Higher Educ 1995;20:25-36.

33. Tartwijk J van, Wubbels T. Evalueren van leervorderingen met portfolio's. Onderwijskundig Lexicon (Katern Evaluatie). Alphen aan de Rijn: Samson; 2000.

34. Herman JL, Winters L. Portfolio research: a slim collection. Educ Leadership 1994;52:48-55.

35. Dierick S, Watering G van de, Meijtjens A. De actuele kwaliteit van assessment: ontwikkelingen in de edumetrie. In: Dochy F, Heylen L, Mosselaer H van de, editors. Assessment in onderwijs: nieuwe toetsvormen en examinering in studentgericht onderwijs en competentiegericht onderwijs. Utrecht: Uitgeverij Lemma; 2002. p. 91-122.

\section{De auteurs:}

Drs. J. Beullens is psycholoog en wetenschappelijk medewerker.

Drs. A. Deketelaere is onderwijskundige en wetenschappelijk medewerker.

Prof. dr. E. Struyf is onderwijskundige en diensthoofd. Alle auteurs zijn verbonden aan de Dienst Onderwijs Geneeskunde van de Faculteit Geneeskunde van de Katholieke Universiteit Leuven.

Correspondentieadres:

Drs. Johan Beullens, Dienst Onderwijs Geneeskunde Faculteit Geneeskunde, KU Leuven, Minderbroedersstraat 17, B-3000Leuven, België; Johan.Beullens@med.kuleuven.ac.be.

\section{Summary}

Introduction: The portfolio is a collection of materials presented as testimony that learning has occurred. During the past decade, its use in medical education has shown a steady increase. This article presents a review of the literature on the importance and value of the portfolio in medical education.

Method: We searched Medline and PsycInfo for articles on medical education with 'portfolio' as keyword.

Results: The portfolio appeared to be used at all levels of medical education. Definition and function depended on the educational context, the level of training and the teachers' objectives. In all cases the portfolio was used as a learning tool and it was often also used for summative assessment. Students' and teachers' attitudes varied between studies and between different aspects within a study. Teachers and examiners often looked more favourably on the portfolio than did the students. The students' main concern was the actual implementation of the portfolio. The portfolio's psychometric properties, in particular its low reliability, did not justify its use for summative assessment purposes.

Discussion: More research will be needed to resolve the doubts surrounding the reliability of the portfolio for summative assessment. There appear to be three potential positions with respect to the portfolio as an assessment instrument: (1) reserve the use of the portfolio for formative assessment, (2) try to satisfy the usual psychometric requirements or (3) establish a different form of quality control. (Beullens J, Deketelaere A, Struyf E. The attitudes towards and psychometric properties of portfolios in medical education: a literature review. Dutch Journal of Medical Education 2004;23(4): 186-195.) 